\title{
Using lonely hearts adverts and tweets to engage students in critical evaluation
}

Authors: Sarah Willis and Doug Steinke, Manchester Pharmacy School, The University of Manchester

Background: Core research skills such as analysis, critical evaluation and synthesis of new information, and attributes including ways of thinking about collecting and processing new information have been recognised as important for advancing the pharmacy profession and as enhancing the profession's ability to provide patientcentred care. ${ }^{1}$ Despite this, few studies examine how to engage students effectively in undergraduate research training to develop these skills and attributes. ${ }^{2}$

Description of work: To develop critical reading skills we introduced a "journal club" to the third year Integrated Research Skills course. Prior to the journal club, lectures were delivered on the research design and interpretation of research findings to familiarise students with the research language being used during journal club. The journal club involved critical evaluation of research papers, discussion of research design, methods of analysis (both quantitative and qualitative) and assessment of the clinical significance of papers. Journal club discussions took place in a small group setting and were led by two experienced pharmacy practice researchers. At the end of the session the students were asked to work in teams to produce either a tweet or a lonely hearts advert about a paper discussed during journal club to practise summarising key findings in preparation for one of their assessments for the unit - a 500 word précis of a research article.

Proposed evaluation: While a systematic review of the effectiveness of journal clubs $^{3}$ identified many features of best practice we adopted, we intend to evaluate the journal club using focus groups with $4^{\text {th }}$ years to explore how effective our club was in developing the intended skills and attitudes. Based on findings from these focus groups we will then survey students to determine the extent to which the journal club was perceived as effective in relation to developing a number skills and attributes needed to support them in their $4^{\text {th }}$ year projects. ${ }^{3}$

\section{References}

1. American Association of Colleges of Pharmacy: Commission to Implement Change in Pharmaceutical Education. Background Paper II: entry level, curricular outcomes, curricular content and educational process. http://www.aacp.org/resources/historicaldocuments/Documents/BackgroundPaper2.pdf Accessed 28th March 2014.

2. Ward B, Dickson-Swift V, James E, Snow P, Spark J, Verrinder A. Incorporating research training into undergraduate pharmacy courses: A case study from Australia. Pharmacy Education 2008; 8 (1)

3. Deenadayalan Y, Grimmer-Somers K, Prior M, Kumar S. How to run an effective journal club: a systematic review. Journal of Evaluation in Clinical Practice 2008 Oct;14(5):898911. 